\title{
THE IDENTITY OF AN INTRODUCED PSYCHID, FUMEA CASTA PALLAS (Lepidoptera, Psychidæ)
}

By Frank Morton Jones and Donald W. Farquhar

When in 1931 the larvae and larval cases of this small Psychid were first observed in the Boston area in Mass., it was apparent that the insect could not be identified with any known North American species of the family. A very few adult males were secured in 1932, and these sufficed to refer the insect to the European genus Fumea, hitherto unrecognized in the western hemisphere, and to indicate that we were dealing with an introduced species. Abundant material of both sexes, bred in 1933, confirmed the generic reference and permitted a careful comparison with exotic material and the literature of the genus. Since the insect has already extended its range in two States and is destined to take permanent place in our fauna, it seems advisable, in addition to the biological notes included in the preceding paper, to put on record those details of its structure which should suffice for its ready recognition in this country.

Fumea, in much of its extensive European literature, obviously has been made to include species structurally divergent, and even under identical specific names there has been such lack of agreement that mixed series or mistaken identities seem the only explanation. We have profited by the careful work of Chapman, of Tutt, and of Burrows, and have accepted their identifications of casta Pallas, the most abundant and widely distributed species of the genus, as the basis of our comparisons. That some of the characters we describe and illustrate should be generic rather than specific, is necessitated by the confusion of literature we have indicated. In| addition to the general habitus of the insect, we have found useful for comparison the following characters:

Venation, wings of male (Plate 3, fig. 1).-This Psychid. is an 11-7 veined insect. In both wings the media divides 
the cell and does not fork within the cell. On the fore wing, the 1st anal does not reach the margin, and the 2 nd and 3rd anals, coincident from near the base, extend to the margin without fork or branch; some variation exists in the origin of the two lower radials, which may arise from a point at the cell, may be shortly stemmed to the cell, or may be separated at their origins on the cell.

The hind wing has three anal veins, the 2nd sometimes tending toward union with the 1st by exhibiting a slight angulation and trace of a spur; the radius and subcosta are not joined beyond the base; $\mathrm{M}_{1}$ may arise as in the figure, or as a direct continuation of the media.

This is all in accord with Fumea casta as illustrated by Chapman, but not in agreement with Bruandia and Proutia (which have media of fore wings forked within the cell), included under Fumea by Seitz.

Legs of male (Plate 3, fig. 5).--In Fumea and its allies the length of the anterior tibial spur (the epiphysis) has been extensively used in the separation of genera and species. Chapman's measurements, thus used and quoted, though designated as spur ratios, really relate to "the ratio of the length of the tibia beyond the origin of the spur, to the whole length of the tibia." For Fumea (excluding germanica) Chapman gives this ratio as .77-.81. This range is evidently too narrow, for Burrows, who inherited Chapman's collection and added to it, measured 236 Fumeas (including Chapman's series), and found a ratio range of .72 to .81 . Evidently the method of preparation and measurement, as well as individual variation, affect the rigid application of this character.

Balsam mounts of the legs of Massachusetts Fumeas give us an average ratio of .76 , with a minimum and maximum of .72 and .79 .

Legs of female (Plate 3, fig. 6).-These agree with casta in having five joints to the tarsi of all legs. A single vestigial apical spur is sometimes present on the fore tibia, rarely present on the mid-tibia; may be present on one tibia, absent from the corresponding opposite tibia of the same insect. When present, it varies in shape from almost globular to elongate with a length twice its diameter. These 
conditions prevail in both English and American examples.

In both sexes, irregularity exists in the relative length of the legs (the third pair always the longest), due chiefly to the variability of the first tarsal joint.

Antenna of the male (Plate 3, fig. 2).-Bipectinate from the third or fourth joint. The third joint, sometimes showing a short pectination, is usually more or less fused with the fourth; and the distal joint may be simple or bipectinate, according to its degree of fusion with the next. The longest pectination (balsam mount) measures $.52 \mathrm{~mm}$. The shaft and dorsum of the pectinations are clothed in appressed scales (these and the fine hairs of the pectinations not shown in the figure). The apparent number of antennal joints is usually 20 , but these by fusion may be reduced to 18 or 19 , and in one instance we were able to count 21 joints.

Antenna of female (Plate 3, fig. 7 ).-Simple, bead-like, consisting of 13 joints of irregular size. Occasionally 14 joints may be detected.

Abdominal plates and genitalia of male (Plate 3, figs. 3 and 4).-By direct comparison we detect no essential differences in these structures, between our Massachusetts insects and casta as identified by English entomologists.

Ovipositor of female (Plate 3, fig. 8).-The ovipositor is capable of extrusion until it equals the entire length of the remainder of the insect. Balsam mounts of the female abdomen show prominently three sets (of 2 each) of hairlike black rods, which function in the telescopic mechanism. Mounts from English casta show these rods to be identical in number, shape, and position with those of Massachusetts insects; and this apparent identity extends to relative length of the three sets, with such exactness that specific identity of the insects seems assured. Preparations by identical technique, drawn and measured at the same magnification, for the three sets of rods give these ratios of length:

5 English casta, from the

Chapman and Burrows collections $36: 48: 147$

3 Massachusetts casta

$36: 50: 147$ 


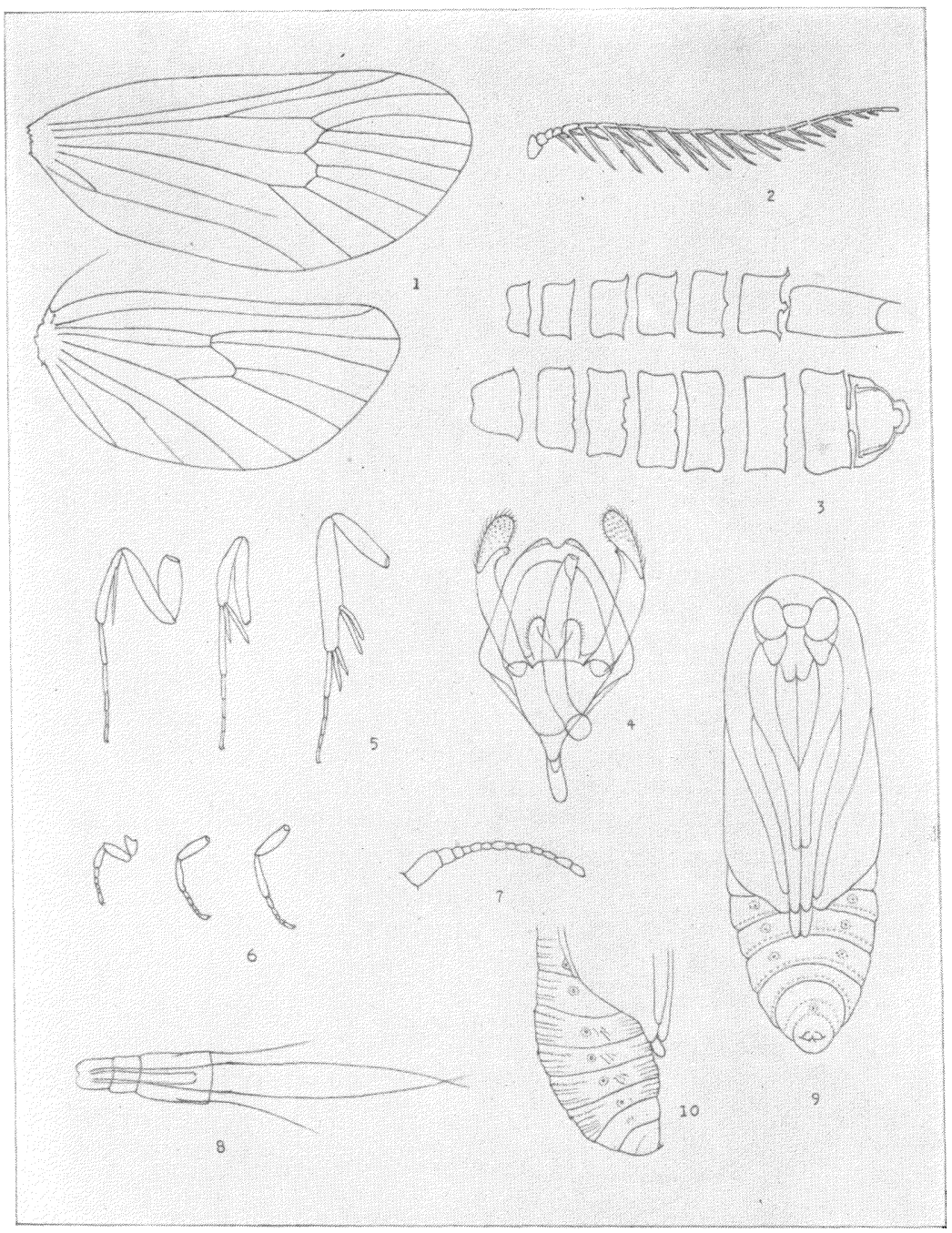

Some Structures of an Introduced Psychid

(Fumea casta, PALLAS )

1. Venation of male

2. Antenna of male

3. Abdominal plates of male

4. Genitalia of male

5. Legs of male
$(10 \mathrm{x})$

(12x)

$(12 \mathrm{x})$

$(37 x)$

(10x)
6. Legs of female

7. Antenna of female

8. Rods of ovipositor

9. Male pupa, ventral view

10. Male pupa, lateral view (10x)

$(27 \mathrm{x})$

(10x)

(11x)

(11x) 
Pupa of male (Plate 3, figs. 9 and 10).-In the male pupa of Fumea, the fore wings, the legs, and the antennæ are free at their apices, standing out slightly from the abdomen, so that according to the degree of its extension they may overlap the fifth abdominal segment or may barely reach its anterior margin. As far as we have been able to make comparison, the general characters of the pupa as shown by our illustration are in accord with English casta.

We are aware that the form of the generic name (Tutt, British Lepidoptera, II, 317, 318, 1900), its genotype, and the properly included species, are all subjects for differences of opinion and will require review, and that in the European literature the status of casta Pallas, with reference to its synonyms, its geographical races, and the number of possibly distinct but closely related species remains a matter of opinion. Tutt follows Chapman in treating intermediella Bruand as a race intergrading with casta, while Seitz considers intermediella a pure synonym. By Tutt's analysis, in this "protean species represented by various local races," our insect in size and structure comes nearest to variety intermediella, which is supposed to be of more frequent occurrence on the European mainland rather than in England. In view of the impossibility of determining the place-origin of our insect and of the intergradation of the partially localized and illy-defined varieties or races of casta, we believe that for the present this recent addition to our fauna may be most satisfactorily designated in our literature by the oldest and best-known name for this widely-distributed insect, Fumea casta Pallas. 

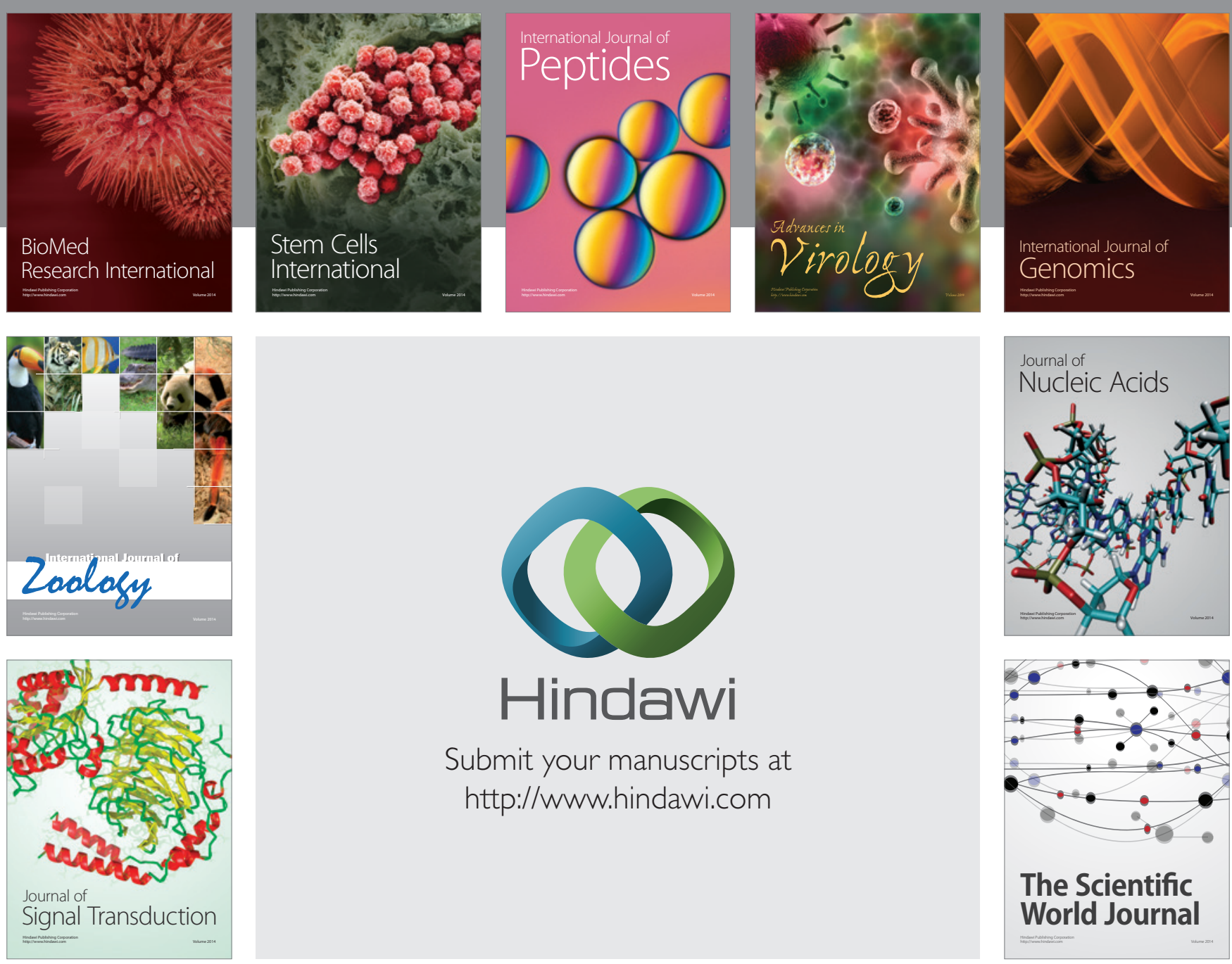

Submit your manuscripts at

http://www.hindawi.com
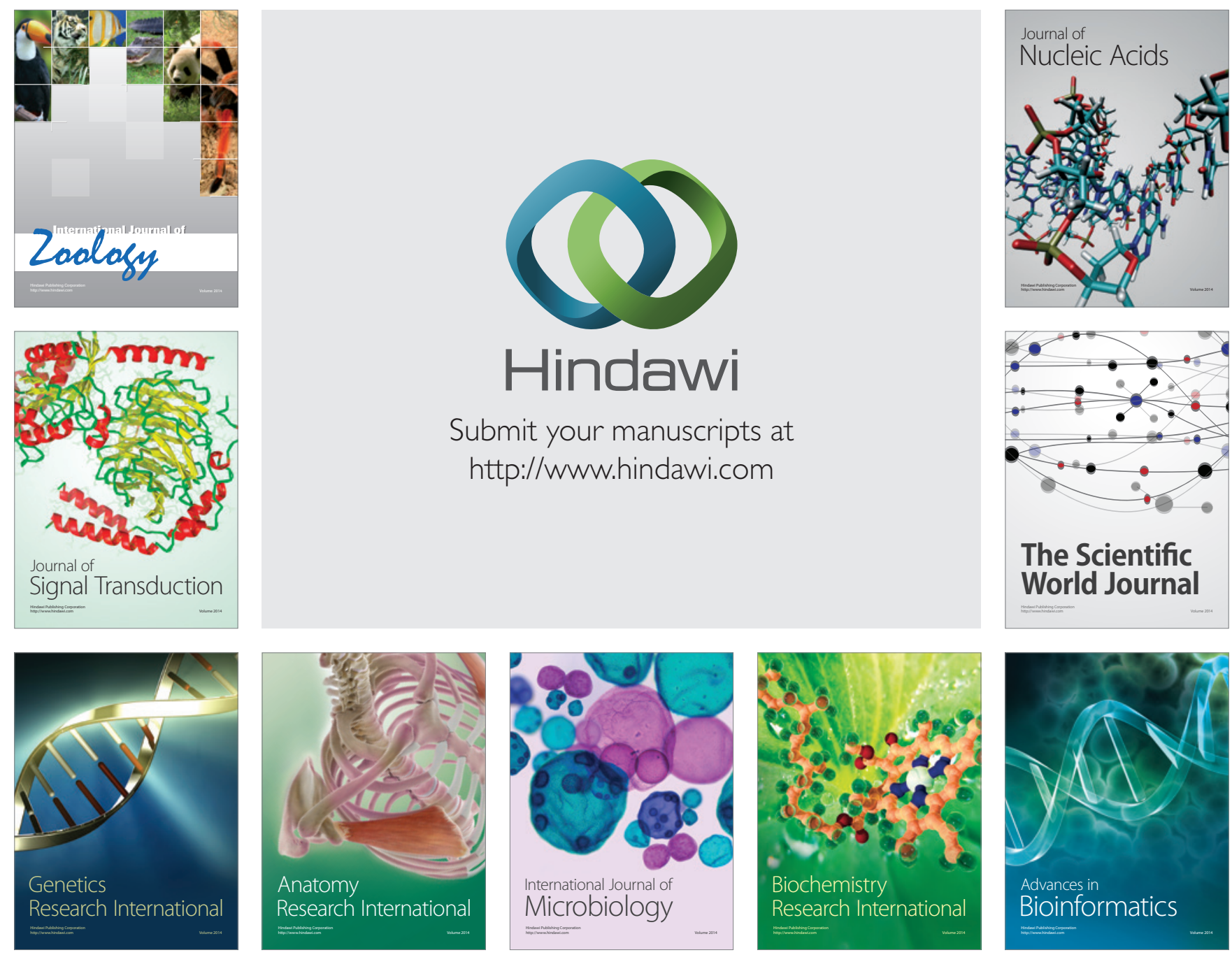

The Scientific World Journal
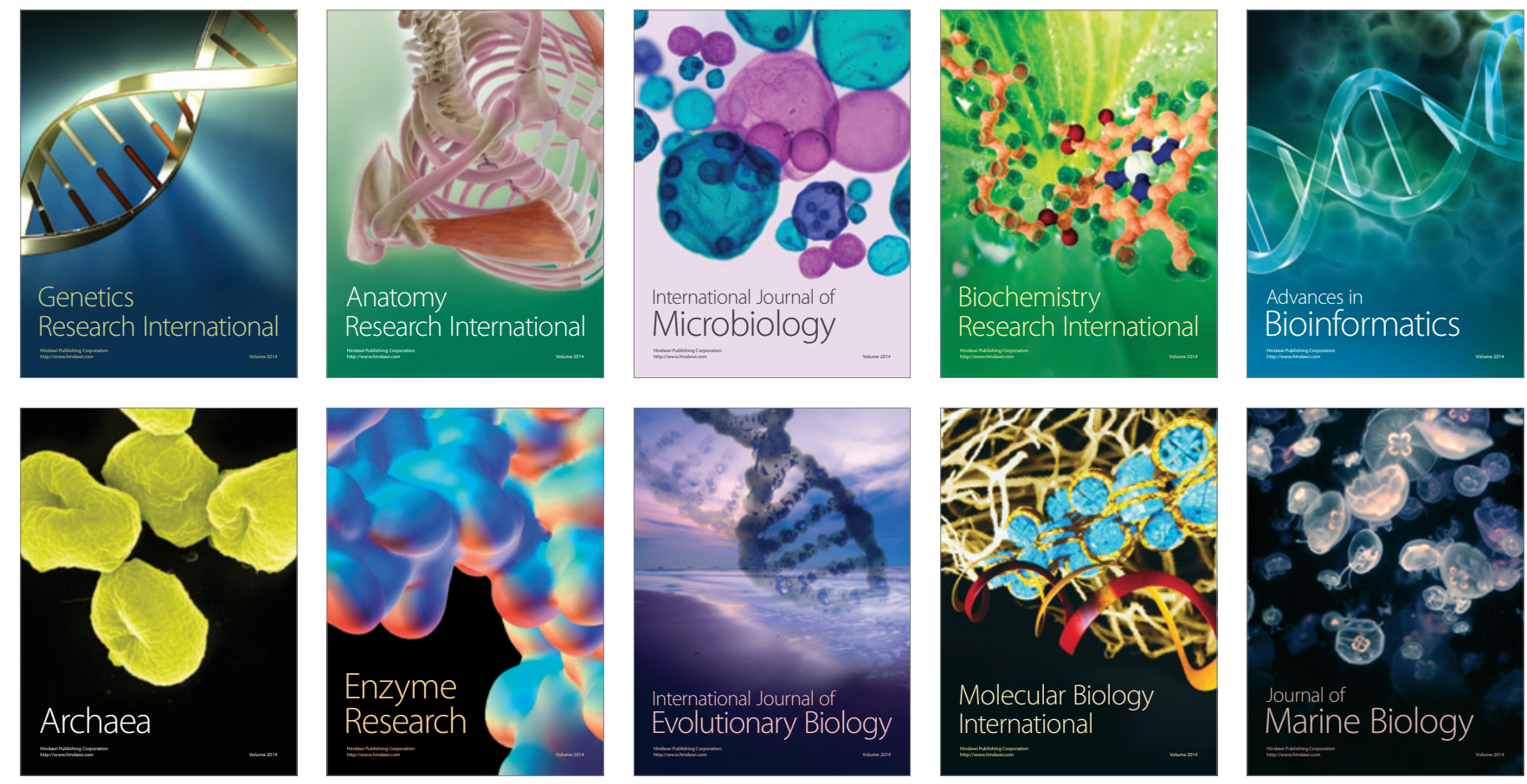